\title{
Objetos y materiales en la escuela infantil: historias que se recogen, se viven y se inician
}

\section{Cristina Sendra Mocholí}

Universitat de València, Valencia, España

mail: cristina.sendraauv.es

ORCID: https://orcid.org/0000-0001-9218-7041

\author{
Clara Arbiol González \\ Universitat de València, Valencia, España \\ mail: clara.arbiolduv.es \\ ORCID: https://orcid.org/0000-0003-1024-6402
}

\section{RESUMEN}

En este trabajo intentamos mostrar el aula de educación infantil como un espacio y un tiempo de historias que se recogen, se viven y se inician. El texto es fruto del estudio que hemos realizado en una escuela pública de una población cercana a la ciudad de Valencia. Es una escuela peculiar pues está en un paraje natural, donde el tiempo parece desacelerarse. Durante dos cursos hemos acompañado a las maestras y a las criaturas en dos aulas de 5 y 3 años respectivamente. Nuestra investigación de carácter narrativo explora, desde distintos puntos de vista, los procesos de creación curricular que observábamos en las aulas. En nuestra práctica de observación recogemos hilos con los que enlazar historias que nos muestran cómo el currículum se va creando en la escuela. En este texto exploraremos uno de esos hilos de nuestro estudio: el papel que los materiales tienen en la vida del aula, cómo determinados objetos (libros, elementos naturales, fotografías...) conectan la vida del aula con la vida de las niñas y los niños y sus historias familiares, y cómo cuando las maestras acogen estos materiales y les hacen espacio, aparecen nuevas historias para vivirse desde ellas..

Palabras Clave: Creación curricular, materiales escolares, educación infantil, documentación pedagógica, indagación narrativa.

\section{Objects and materials in early childhood education: collected, lived, and prompted stories}

\section{ABSTRACT}

In this paper we aim to present the early childhood education classroom as a space and a time of collected, lived, and prompted stories. This text is the result of a study conducted in a state school located in a village near Valencia. It is a singular school, for it is situated in a nature park, where time seems to decelerate. For two school years, we have been alongside teachers and children in two classrooms of ages 5 and 3 respectively. Our investigation - which is of narrative character - explores from different points of view the curriculummaking processes observed in the classrooms.

In our observation practice, we gather threads with which to connect stories that show how the curriculum is created within the school. In this paper we will explore one of these threads of our study: the role materials play in the life of the classroom, the way in which certain objects (books, natural elements, photographs...) connect the life of the classroom to the life of the children and their family stories, and how, when teachers embrace these materials and give them a space, new stories to be experienced spring up.

Keywords: Curriculum-making, school materials, early childhood education, pedagogical documentation, narrative inquiry.

ISSN: 0210-2773

DOI: https://doi.org/10.17811/rifie.50.3.2021.689-696 


\section{Introducción: hilos en la creación curricular}

Esta investigación nace con el proyecto de investigación RECREA $^{1}$ donde nos preguntábamos, en primer lugar, por las experiencias de creación curricular que se producen tanto en la formación inicial del profesorado como en la escuela y, en segundo lugar, por las prácticas de enseñanza que podemos ofrecer a los futuros maestros y maestras que les permitan desarrollar procesos de creación curricular en la escuela. En este texto presentamos una parte del estudio que hemos realizado sobre las experiencias de creación curricular en la escuela. Hemos acompañado a dos maestras de educación infantil y a las criaturas de 5 años, en el primer curso que estuvimos en la escuela, y a las de 3 años en el siguiente. Durante ese tiempo, hemos ido encontrando la forma de estar -y estar como investigadoras- en el aula, acompañando la vida de la clase desde un lugar inspirado en la documentación pedagógica (Hoyuelos, 2006 y 2007; Malaguzzi, 2001; Rinaldi, 2011) para observar, documentar y narrar como vía para atisbar las líneas que abrían la creación curricular. El proyecto no pretendía tanto comprobar una teoría o un concepto sobre la creación curricular como poder abrir la pregunta allá donde encontramos indicios de una práctica de composición que nos remiten a una creación de saber, a una disposición de materiales, de tiempo y espacio y a un cuidado de la experiencia para pensar el currículum. Poder explorar la vida en la escuela para entrever hilos que nos hacen pensar en actos de creación o composición curricular en la relación entre las maestras y las criaturas, entre las criaturas, con el entorno, con lo otro de la escuela, con lo que está fuera de la escuela, pero también llega a ella. Y hacerlo a través de las historias que allá se viven, por eso, esta mirada, nuestra mirada, es una mirada narrativa a la experiencia de la escuela y a la experiencia del currículum y su composición.

Narrar el currículum significa vivirlo, pensarlo y mostrarlo como una historia. Una historia de lo que va aconteciendo en las escuelas. Una historia de creación colectiva y, también, personal (Aoki, 1993; Martín et al., 2019). Una historia determinada por cada una de las personas que comparten un curso escolar (Clandinin et al., 2011; Huber et al., 2016): los niños y las niñas, las maestras y los maestros, las familias, las distintas personas que trabajan en la escuela (personal de conserjería, de limpieza, educadores y educadoras, personal de cocina...) e, incluso, por las personas que también, de alguna manera, han participado durante el curso (el cuentacuentos, la hornera, el cartero, la jardinera del parque...). Así pues, el currículum, la historia de un curso escolar, no sería la misma sin cada una de estas personas.

Como investigadoras del currículum, nosotras hemos puesto nuestra atención en dos aulas de Educación Infantil: en dos maestras, Imma y Consol, y en los niños y las niñas que atienden, cuidan y educan. $Y$ hemos intentado captar historias que puedan ayudar a mostrar, a pensar y a reflexionar sobre cómo se va creando el currículum; a mostrar, a través de la narración, cómo va emergiendo el currículum.

\section{La práctica de investigación}

La experiencia de investigación que presentamos tuvo lugar en el centro de educación infantil y primaria Lluís de Santàngel. Una escuela de una pequeña pedanía, El Saler, que depende del municipio de Valencia y que forma parte de un entorno natural protegido: el Parque Natural de la Albufera. Conocida como la escuela de la Devesa del Saler, se encuentra situada en medio de un bosque mediterráneo (formado por pinos, lentiscos, zarzaparrillas, coscojas, mirtos, palmitos...) y sobre un suelo de arena que nos recuerda que, sólo hace unos pocos miles de años, aquello era mar. El lago de la Albufera, los campos de arroz, las dunas, la playa y el mar completan el entorno natural de esta escuela. Un hogar para un gran número de animales (aves, reptiles, pequeños invertebrados...) y un lugar de paso, en su viaje migratorio anual al norte de Europa en verano o hacia África en invierno, para muchas aves. Un espacio envuelto de naturaleza, a escasos diez kilómetros de la ciudad de Valencia, en el que la luz parece más clara, el aire más puro, el tiempo más pausado...

Como se muestra en la tabla 1, nuestra práctica de investigación consistió en observar dejándonos decir por los pequeños momentos que iban componiendo el día a día en la escuela. Una observación que también significó, en algunas ocasiones, participar activamente en el aula: contar un cuento, aportar algunos objetos y materiales, explicar alguna curiosidad, atender y cuidar a las criaturas (atar cordones de zapatos, lavar manos, quitar mocos, poner y quitar chaquetas, abrigos, gorros, guantes, baberos...). Momentos que, sin duda, han enriquecido nuestra observación y nos han aportado nuevas perspectivas.

Tabla 1

Esquema que muestra las fases seguidas para la elaboración de las historias

Fases

(1) Observar y participar

(2) Documentar

(3) Compartir, conversar y reflexionar

(4) Narrar
Algunas indicaciones

Observación y participación atentas y respetuosas con la cotidianidad del aula y de la escuela

A través de anotaciones en el diario de campo y de fotografías. El foco se sitúa en captar cómo se va componiendo el currículum

Compartir algunos de los materiales de documentación con las maestras y parte del grupo de investigación y reflexionar atendiendo a los distintos puntos de vista

Escritura y reescritura de las historias relacionadas con la creación curricular que se comparten con el grupo de investigación y se nutren con sus aportaciones. Elaboración definitiva de las historias con las que mostrar y pensar sobre los procesos de creación curricular en la escuela con el profesorado en formación

Nota. La tabla muestra en qué consiste nuestra práctica de investigación inspirada en la indagación narrativa y en la documentación pedagógica

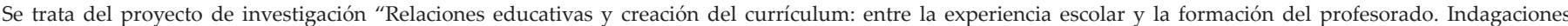

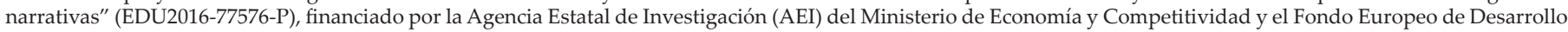
Regional (FEDER, UE). 
Al mismo tiempo, documentamos aquello que iba aconteciendo en la escuela, poniendo el foco en ese intento de captar cómo se iba componiendo el currículum, a través de anotaciones en nuestros diarios de campo. En ocasiones, también utilizamos la fotografía. Posteriormente, estos documentos nos sirvieron para conversar entre nosotras, con las maestras y con otras investigadoras e investigadores del proyecto. Algunas de estas conversaciones fueron registradas en audio y, después, transcritas. Finalmente, a partir de estos materiales hemos narrado las historias con las que mostrar y reflexionar sobre cómo se va creando el currículum en estas aulas de Educación Infantil. Historias que, además, se podrán leer, compartir y conversar sobre ellas en las clases de formación inicial (y continua) del profesorado.

Con la finalidad de proteger la intimidad de los niños y las niñas, hemos utilizado únicamente su inicial para nombrarlos. Sus palabras y las de las maestras han sido traducidas ya que la lengua que se utiliza en la escuela es el valenciano.

Por último, nos gustaría destacar la enorme generosidad y la disposición de las maestras que nos han acogido en sus aulas. No sólo nos han dejado estar allí sino que nos han hecho sentir que formábamos parte de la escuela. Y nos han regalado un saber que ha transformado nuestras clases en la universidad llenándolas de vida.

\section{Historias con las que mostrar algo de lo que sucede en la escuela}

Para nosotras, un hilo a través del cual reseguir la creación curricular en la escuela, de la mano de las maestras, fueron las historias (Sendra y Arbiol, 2019). Aquellas que nacían y crecían a partir de elementos que aparecían en las aulas y que a su vez, representaban la posibilidad de hacer presentes otras historias que forman parte de las vidas de los niños y las niñas, de esos otros mundos (Molina, 2017) que habitan los niños y las niñas. Y que encuentran en el aula, espacios para contar-revivir-recontar (Clandinin, 2013), para hacer presente la forma en la que participan de esos diferentes mundos. Así, pueden, las criaturas pero también las maestras, vivirse a través de las historias. Elaborar un relato de quiénes son, de quien son, también, en la escuela.

En este texto presentamos algunas historias que muestran cómo algunos de los objetos y materiales (libros, elementos naturales, fotografías...) que traen regularmente al aula los niños y las niñas (aunque también, en algunas ocasiones, las maestras, otras personas vinculadas a la escuela, las familias o, incluso, nosotras mismas) van ligados a una historia personal y, a su vez, abren la posibilidad de vivir nuevas historias al ser recibidos en el aula. Objetos y materiales que conectan la vida del aula con la vida de los niños y las niñas y sus historias familiares. Objetos y materiales que son acogidos por las maestras, otorgándoles un tiempo y un espacio en el aula, permitiendo, de esta manera, vivir nuevas historias, crear currículum.

La primera historia que relatamos tuvo lugar en nuestro primer día en la escuela junto con las maestras. La segunda narra algunos momentos que transcurren durante la asamblea: un lugar y un tiempo para contar, conectar y comenzar nuevas historias en nuestra escuela. La tercera historia muestra el aula como espacio de conversación y cómo en la conversación se hace presente el mundo de las criaturas.

\section{Pequeñas cajas de cartón: un lugar íntimo en la escuela}

Las maestras ya nos mostraron en nuestro primer encuentro en la escuela, entre otras muchas cosas, un objeto cotidiano, sencillo y humilde que utilizaban, aunque ellas no nos lo explicaron de esta manera, como un instrumento que acogía y ofrecía la posibilidad de vivir nuevas historias en la escuela: la caja.

Era una mañana de julio. La escuela estaba extrañamente tranquila y silenciosa. Nosotras éramos casi sus únicas habitantes. Conversábamos, caminábamos y las maestras nos iban enseñando los distintos espacios escolares y las aulas de infantil. Nos contaron que el próximo curso será el tercero que compartirán con las mismas criaturas: niños y niñas que comenzaron su paso por la escuela infantil con tres años (o casi tres) y que lo acabarán con seis años (o casi seis). Ellas suelen conservar algunos objetos y materiales a lo largo de estos tres cursos. Y, entre ellos, nos mostraron unas pequeñas cajas de cartón.

Cada criatura tenía una caja. Por fuera eran todas iguales, únicamente se diferenciaban por el nombre del niño o de la niña que llevaba escrito. Sin embargo, cada una contenía en su interior cosas diferentes. A lo largo de los tres cursos, las criaturas van guardando en ellas sus tesoros: objetos y materiales que ha ido conservando desde los tres años. Cajas que, de alguna manera, atesoraban algunas de sus historias vividas y de sus recuerdos infantiles. ¿Y qué desea conservar una criatura? Con mucho cuidado, las maestras abrieron una de esas cajas. Contenía unas piedrecitas, una hoja seca, una entrada de cine, una postal de viaje y una fotografía familiar.

Aquellas cajas nos hablaban de las criaturas. Cajas distintas, con distintos objetos y materiales. Cajas que cada niño y niña iban componiendo con cosas sencillas e importantes. Cajas con objetos y materiales que esconden historias, historias que los niños y las niñas podrán recordar cada vez que decidan abrir su caja. Y que podrán contar a los otros y a las otras si así lo desean. Cajas que seguro ayudan a aumentar el sentimiento de afecto entre las criaturas y entre las criaturas y las maestras ya que acercan y unen historias y recuerdos. Cajas que contienen cosas valiosas para las criaturas y que forman parte también de la escuela.

Más tarde, cuando comenzamos a acudir algunos días a la escuela, nos dimos cuenta de que estas pequeñas cajas de cartón no eran las únicas. Había más cajas por el aula. Cajas también especiales, con nombres singulares: caja de las cosas delicadas, caja de las cosas que traemos de casa, un terrario, que actuaba como caja de los materiales naturales más efímeros (una flor, una hoja, una pequeña rama...). Cajas que se convierten en una especie de lugar en el que se recopilan y almacenan objetos y materiales, historias y recuerdos. La caja, un instrumento que acoge historias y ofrece la posibilidad de vivir nuevas historias en la escuela.

La asamblea: un lugar para contar historias, un lugar para iniciar nuevas historias

El inicio de la jornada escolar en nuestras aulas de infantil es tranquilo y alegre. Las maestras llegan un poco antes, preparan el aula y esperan en su puerta la llegada de las criaturas. La mayoría vienen a la escuela en diferentes autobuses escolares por lo que van entrando en grupos pequeños al aula: la maestra puede dedicar unos instantes a cada criatura para darle la bienvenida, ofrecerle unas palabras amables y afectuosas, y atenderla si lo necesita (el abrigo, la mochila...). Hay calma y mucha alegría en el nuevo día que comienza en la escuela.

Los niños y las niñas entran encantados en el aula. Dentro les esperan los cuentos, los álbumes ilustrados, los cómics o los pequeños libros de poemas infantiles. Preparados por la maestra, estos libros se encuentran encima de las mesas, esperándoles. 
También pueden acceder a otros que están en las estanterías, si lo desean. Y los miran, señalan las ilustraciones que aparecen y los comentan entre ellos. Nada más comenzar la jornada escolar se produce este momento delicioso de lectura libre, acompañada, compartida, conversada.

Cuando ya parece que han llegado todos y todas, se guardan los libros y es el momento en el que da comienzo la asamblea. Los niños y las niñas se sientan en el suelo, muy juntos, formando dos filas que miran hacia la maestra. Se dan los buenos días a cada uno y a cada una, se anota qué día de la semana es, se comenta el tiempo que hace. Podríamos considerar que la asamblea es rutinaria, que apenas posibilita el movimiento a las criaturas que deben pasar la mayor parte del tiempo sentadas. Pero, a pesar de todo, en nuestras aulas es clave: es el momento en el que se acoge aquello que cada una y cada uno trae a la escuela.

Entre aquello que traen las criaturas, siempre, cada día, aparecían lo que ellas y ellos llamaban "noticias" importantes. Estas noticias eran escuchadas por todos y todas, y comentadas en el aula (asamblea del 31 de enero de 2019, aula de 3 años):

A: Mi mamá tiene un bebé en la barriguita. Y yo le toco la barriguita.

\section{Y, entonces, se inicia una conversación:}

L: Mi hermanito Mateo ya ha nacido y come de la teta de mi mamá.

P: En mi casa ya han montado la cuna porqué mi hermanito Teo nacerá esta semana.

Con la ayuda de la maestra, se habla de los bebés que conocen: hermanos y hermanas, primos y primas, otros bebés... De esta manera, se conversa a partir de sus propias experiencias, de sus inquietudes. Y las criaturas ofrecen aquellas historias que desean que formen parte de la escuela.

Pero además de estas "noticias", en muchas ocasiones, lo que traen los niños y las niñas de sus casas son objetos que, claro, también esconden historias (y que, aunque nos sorprenda a las personas adultas, la mayoría de las veces, no son juguetes). K nos trajo y nos enseñó su linterna y, junto con ella, nos contó su historia (asamblea del 14 de febrero de 2019, aula de 3 años):

K: Hace luz. Por las noches buscamos cosas debajo de mi cama y de la de mi hermana.

Por supuesto, otras criaturas también tienen linternas y lo hacen saber durante la asamblea. Se habla durante un ratito de las linternas, de la luz, de la oscuridad, del día, de la noche. Una vez más, hay tiempo para la conversación, para contarnos historias. Y la linterna se deja en la caja de las cosas que traemos de casa. Esa caja que actúa como receptora, contenedora y posibilitadora de historias. Seguro que con la linterna de K se vivirán nuevas historias en la escuela. Eso sí, hay dos normas con los objetos de esta caja: únicamente se utilizan en los momentos de juego libre y pueden volver a casa cuando la criatura que lo trajo lo desee.

Otras veces los niños y las niñas aportan materiales naturales. D nos enseñó unas conchas de mar que había recogido con su familia en la playa. Se trataba de valvas de diferentes bivalvos. Unas eran lisas (como las tellinas) y otras eran rugosas (como los berberechos). Las conchas fueron pasando por las manos de las criaturas que las observaron, las tocaron, las olieron (asamblea del 18 de octubre de 2017, aula de 5 años):

\section{L: Huelen a playa.}

La maestra les invitó a que distinguieran entre las lisas y las rugosas. Las criaturas hablaban de conchas finas y suaves, y de conchas arrugadas:

P: Todas son lisas.

Maestra: Obsérvalas bien, unas son lisas y otras son rugosas.

P: Pero por dentro todas son lisas.

Nuestro afán clasificatorio adulto se derrumbaba ante la evidencia que nos mostraba P. Hubo que rectificar:

Maestra: Tienes razón. Todas son finas y suaves por dentro. Entonces, vamos a distinguir entre las que son lisas, finas y suaves por fuera y las que son rugosas y arrugadas por fuera.

Después, las conchas del mar se colocaron en la caja de las cosas delicadas dónde se guardan las cosas que traen las criaturas que pueden romperse fácilmente y que, por tanto, debemos tratar con más delicadeza. Una nueva caja llena objetos y materiales que nos hablan de historias que traen los niños y las niñas, que se muestran en la asamblea y que se ofrecen en esta caja tan especial para crear nuevas historias que, como los objetos que contiene, estarán llenas de delicadeza, de sensibilidad, de cuidado.

Ese mismo día, D también trajo de su excursión a la playa unas pequeñas ramitas de un arbusto (no supimos identificarlo). Quizá para la mayoría de adultos esas ramitas no tendrían mucho sentido. Incluso sugerirían a D que las tirara a la papelera. Pero eran las ramitas de D, que cogió con su familia, que pensó en su escuela mientras recogía aquellos elementos naturales que le resultaban tan bonitos y que quiso guardarlos para compartirlos.

En la asamblea observamos las pequeñas hojas de las ramitas, su forma, su color. J acercó unas lupas del rincón de naturaleza para observarlas mejor. Y, finalmente, se guardaron en una caja diferente: un terrario. Aquí se guardan aquellos materiales que son bellos y efímeros como hojas o flores silvestres que recogen las criaturas, o como estas ramitas de D. El terrario es como una caja pero de cristal, transparente. Deja ver su contenido, por lo que se depositan aquellos materiales que por su belleza vale la pena observar. Materiales que irán cambiando y que permitirán, de esta manera, visualizar el paso del tiempo. Materiales que, en algún momento, se tendrán que retirar y volverán a la tierra para completar su ciclo, para volver a formar parte de la naturaleza.

En la asamblea también se muestran los libros que las criaturas traen de sus casas con el deseo de compartirlos y de que también formen parte de la escuela. Estos libros se guardan en una estantería especial y, como los objetos, vuelven a casa cuando la criatura lo desea. La mayoría de los libros que traen son sobre animales: les fascinan.

Desde que L trajo un libro sobre los "bichos", la maestra lee una página cada día durante la asamblea de la mañana. Y si se le olvida, los niños y las niñas se lo recuerdan. En la página de hoy aparece un escarabajo verde, brillante y suave (asamblea del 14 de febrero del 2019, aula de 3 años):

O: ¿Está enfadado?

Maestra: No. Esconde sus patas y se queda quieto porque un depredador se lo quiere comer y, así, le engaña.

Y por sugerencia de la maestra, las criaturas se convirtieron en escarabajos verdes y brillantes que, sobre el suelo, esconden las 
patas (las piernas y los brazos) debajo de su cuerpo y ¡consiguen parecer una piedra! Ahora el depredador ya no se los comerá. Convertirse en escarabajo, en mosca, en cocodrilo, en oso polar, una forma maravillosa de acercar el mundo a las criaturas.

En la misma asamblea, P enseñó una ilustración que muestra cómo es un hormiguero por dentro. Durante la asamblea, las criaturas también aportan materiales relacionados con el proyecto que se está trabajando: libros, fotocopias, fotografías, dibujos. Ahora el proyecto trata de las hormigas. Gracias a la ilustración de $P$, se pueden observar los túneles y las galerías que excavan las hormigas, que son como pasillos y habitaciones. Entre todos y todas, recuerdan qué comen las hormigas y reflexionan sobre cómo almacenan la comida en las galerías:

M: A mí me gusta dar de comer a las hormigas.

B: He observado a las hormigas en el parque y ¿sabéis qué?, ique no tienen cara!

Claro, ni los ojos, ni la boca, ni la nariz, ni las orejas de las hormigas son como las nuestras. Y nuevamente, comienza una deliciosa conversación sobre cómo es la cara de las hormigas en la que las criaturas aportan sus ideas al respecto. $\mathrm{Y}$ nos hacen reflexionar a las adultas que allí nos encontramos sobre esas imágenes estereotipadas que ofrecemos a las criaturas, con caras humanas y poco realistas.

Después, los materiales del proyecto se incluirán en un mural, que se va construyendo poco a poco con las distintas aportaciones de las criaturas y de la maestra, o se colocarán sobre una pequeña mesa dedicada a todo aquello relacionado con las hormigas, cada día más llena de contribuciones. Verdaderamente, se trata de un proyecto de todos y de todas. Las paredes y los rincones del aula van contando la historia -las historias- que aparecen en la clase.

Y esta es la asamblea, un lugar en el que se muestran historias que van acercando el mundo a las criaturas a través de los objetos, de los materiales (y de las noticias) que cada una y cada uno trae, al mismo tiempo que se va creando un vínculo de afecto entre todos y todas. Objetos y materiales que tienen un tiempo para ser mostrados y un espacio (como las cajas, estanterías, mesas, murales) para ser conservados y formar parte de la vida del aula. Objetos y materiales con los que se va componiendo la historia del curso, con los que se va creando el currículum que se vive en estas aulas de infantil.

\section{Abrir la conversación en el aula: la posibilidad de contarse}

En la práctica de las maestras, como decíamos, hay un gesto de acogida, que vemos cuando abren el espacio del aula a la conversación. Hay días en que la actividad en el aula consiste en conversar, un conversar nacido en relación a un objeto y que va trayendo el mundo de las niñas y de los niños al aula, y que con ella va tejiendo. El aula, entonces, es una escenificación (Biesta, 2017) de esa relación de diálogo con el mundo en la que consiste aprender: ser sujeto en el mundo.

Cuando volvemos del patio (observación del 8 de noviembre de 2017, aula de 5 años) las niñas y niños de la clase se sientan en la asamblea de nuevo, antes de salir hemos estado hablando de los números, ¡están por todas partes! Las niñas y niños han ido pensando dónde ven números. En la conversación la maestra ha ido animando a pensar, a recordar, de repente les pregunta si se acuerdan cuando entraron en la escuela con tres años. Han crecido, han cambiado y eso nos lo pueden enseñar los números. La maestra saca un medidor de pared de los que tienen dibujos y lo abre, en él hay anotados números: la talla que tenían cuando entraron en Infantil, con el nombre al lado, ahora se medirán y también se pesarán para ver cuánto han crecido. A lo largo de estos tres cursos las maestras han ido guardando dibujos, registros, letras, escritos, composiciones de las criaturas, ahora que estamos cerrando el ciclo reaparecen para componer las historias de cada niño y niña. Recogerán así sus cambios: en el trazo, en el dibujo, en las letras, darán cuenta de lo que han aprendido, de lo que han investigado y han descubierto, de lo que ha sido emocionante, significativo. También de cómo han cambiado, porque las maestras guardan la talla, el peso, la huella de las manos y de los pies, fotografías, con las que las niñas y los niños pueden recorrer y componer una historia del ciclo de infantil.

Cuando hemos llegado esta mañana, entre otras novedades hemos visto un acuario que todavía no tiene peces. El día anterior, $\mathrm{H}$, uno de los niños de la clase con su familia lo trajo para la clase y explicaron cómo había que cuidar a los peces que traerían más adelante. $\mathrm{H}$ también tiene un acuario en casa, así que de alguna manera asume el papel de encargado del acuario, de los peces y de sus cuidados.

Maestra: Ayer cuando vinieron los padres de H, S tuvo una idea.

S: Que podemos poner plantas y cosas para decorar el acuario y que los peces se encuentren más cómodos.

$\mathrm{H}$ : Podemos poner piedrecitas y conchas que hemos traído a clase.

Maestra: Primero tendremos que lavar las piedras para ponerlas en el agua por si acaso. Las plantas son muy delicadas.

S: Hay unas plantas que parecen plantas acuáticas, valen 2 euros o 3 euros.

Maestra: Otra vez nos salen los números, ¿os dais cuenta? Pero sabéis qué pasa, que estas plantas yo no sé cómo se llaman, tendremos que investigar.

En la clase alguien habla de las algas, conocen la posidonia, acuerdan que hay que pensar qué plantas pueden poner en el acuario, si pueden poner algas, si los peces podrán vivir con ellas porque quizás no todas van bien. $\mathrm{H}$ vuelve a hablar de los peces; en casa, dice, tienen un acuario grande. La maestra incide en el cuidado de los peces.

Maestra: Aquí tenemos un problema: ¿estamos, todas y todos, todos los días?

- No

Maestra: ¿Qué días no estamos?

- Sábado y domingo

- Y las vacaciones.

Maestra: ¿Quién les dará de comer?

- Podríamos venir de vez en cuando

Maestra: Pero cuando no estamos, los conserjes cierran la puerta y ponen la alarma.

$\mathrm{H}$ : ¡Ya lo tengo! Les ponemos la comida y los miramos.

Maestra: Pero qué hacemos ¿nos llevamos el acuario?

H: Sí.

Maestra: Pero ¿cómo? Porque pesa, habíais dicho... ¿60 kilos?

H: Si voy con coche, que si no es incómodo.

Maestra: A ver si alguien tiene otra idea.

G: Le podemos dar comida antes de que cierren la escuela, cogemos un vaso de poner comida, ponemos comida y así nos vamos.

Maestra: Es que a lo mejor los peces se la comen toda.

J: Podemos poner dos ojos, como hacíamos el año pasado, para ver qué ha pasado. 
Maestra: O cada sábado se podría quedar un niño o una niña a dormir en la escuela.

$\mathrm{H}$ dice que no le gusta mucho la idea y en ese momento otro niño, I, se pone a llorar. En ese momento entra D llorando también porque le ha pasado algo en la sesión con la maestra de audición y lenguaje, $\mathrm{D}$ es un niño que llora a menudo, la maestra normalmente se pone delante de él y le pregunta, le mira, le acoge, a veces nos cuesta entender lo que le pasa y otras se pasa rápido. $\mathrm{D}$ entra al aula y se queda parado al ver que otro niño está llorando. I está llorando porque no se quiere quedar a dormir. La maestra le hace un gesto para que se acerque a ella y lo abraza, les dice que quizás eso no puede ser, les pregunta qué opinan.

Las niñas y los niños hacen una votación, gana, mayoritariamente, el no. A dice que ella se quedaría para siempre en la clase, y H dice que si no encuentran una solución se llevará el acuario a casa.

Maestra: Tendremos que encontrar una solución- y dirigiéndose a $\mathrm{H}$ - cuando vais al cámping, ¿qué hacéis con los peces que tenéis?

H: Les ponemos comida antes, hay un tubito que le pones comida y va saliendo poco a poco.

Maestra: Esa podría ser una solución.

$\mathrm{H}$ : Pero a veces mi padre, como trabaja, se queda.

Maestra: Pero a veces os vais los cuatro.

A dice que ella se quedaría con los peces y que por la noche se metería en la pecera con ellos. La maestra le pregunta si está segura porque si se queda en la escuela dejaría a R, su hermana, sola.

A: Bueno ahora no me quedaría porque aquí no tengo cama.

La clase se ríe, I se calma. Alguien dice algo de una fiesta de pijamas.

\section{- ¡Aquí en el cole!}

La maestra les dice que la fiesta de pijamas la pueden hacer, pero otro día.

- ¿Aquí en el cole?

Maestra: No.

- ¿En otro cole?

Maestra: No.

- ¿En una casa?

I: En la granja escuela.

Maestra: Claro, porque este curso nos vamos de excursión a la granja escuela y nos quedaremos a dormir allá.

$-¡$ ¡Bien!

\section{Pensar la creación curricular con las historias}

Cuando vemos los materiales, cuando atendemos a las conversaciones que se generan, lo que vemos son diferentes historias que conectan mundos, esos muchos mundos que habitan y traen consigo las criaturas. Cuando se abre el tiempo y la escucha al relato de la excursión de un niño con su familia durante el fin de semana, lo que aparece es un espacio en que experimentar los relatos a través de los que contar y contarse: la historia de una excursión es la historia de la relación con su familia, lo que esa criatura experimenta con su familia que tiene espacio en la escuela. Se hace presente la familia en el aula, pero también quién es él en relación con su madre, con su hermana, con la otra familia con la que fue de excursión... posibilitando que aquello que descubre, lo que ha encontrado, tenga conexión en la clase. Encuentran en este espacio una posibilidad de revivir y componerse desde esas historias diferentes que están atravesando el relato que las criaturas van componiendo sobre quiénes son, sobre quiénes quieren ser. A la vez, poner la mirada en las historias que desencadenan los objetos nos permitía atender a una práctica fundamental en el oficio: la práctica de la acogida. Acompañando a las niñas y a las maestras, nos hemos dado cuenta de que la posibilidad de acoger la historia que trae con un objeto una niña o un niño es el camino para acogerla y acogerlo, darles tiempo y espacio, a cada una y a cada uno (Van Manen, 2010)

Para nosotras, estos momentos eran cruciales, Clandinin et al. (2006) los llaman "momentos de tensión", son momentos en los que se componen las vidas de las criaturas, de las maestras y la escuela. Los podemos pensar como momentos de respuesta a la otra, al otro, momentos en los que está en juego lo que conformamos como historia propia, como historia en común. Una historia que siempre es en relación, en relación con la familia, con los otros y las otras del aula, en relación con el mundo. Una historia que nace en un contexto de atención, requiere de las maestras una disponibilidad a la escucha atenta, a la acogida, como decíamos antes. Un momento delicado, de tensión, pues está en juego también algo fundamental, la forma en la que las criaturas transitan de un mundo a otro, de una historia a otra, está en juego la posibilidad de la continuidad, al otro lado, el peligro de la interrupción, del corte profundo que nos separa. Es aquí donde emerge, como decíamos, la composición curricular, como una práctica de articulación de saberes, experiencia, tiempos y espacios. Tal como dirá Olson (2000, p. 171) "el currículum es lo que las niñas y los niños experimentan situadamente, relacionalmente". Las acciones y las palabras van conformando las vidas en la escuela, en un componer y recomponer, y, en este componer y recomponer, reside otro plano de composición, aquel que tiene que ver con la posibilidad de ser sujeto. El currículum nos aparece como un proceso en que las historias de quienes participan tienen lugar, y a la vez, un espacio que es posible vivir en tanto que historias que se componen y nos componen. La práctica pedagógica de las maestras cuida y ofrece las condiciones para elaborar el relato, poniendo en el centro la experiencia vivida, permitiendo vivirse desde una historia propia, singular. Condiciones que ofrecen la posibilidad de recomponer la propia historia en relación con las historias otras. Dice Delory-Momberger (2007) que con la historia ordenamos, conectamos y damos sentido a las relaciones que nos atraviesan, de esta manera, la historia de quién somos se va conformando, como nuestra subjetividad: no elaboramos un relato porque tenemos una historia sino que tenemos una historia porque elaboramos un relato. Un relato, por otra parte, que siempre es relacional: es provisional, atravesado de los relatos otros así como por trayectos institucionales, familiares, afectivos. Un relato que se va componiendo en esos mundos diferentes que habitamos y nos habitan.

\section{Epílogo}

Las historias que hemos mostrado son anteriores a la declaración del estado de alarma a causa del COVID-19. Este curso escolar (2020-21), con las restricciones debidas a la pandemia, los objetos y los materiales que las criaturas traían a las aulas, 
que mostraban y compartían, sobre todo durante el momento de la asamblea, y que iban ligadas a una historia personal (el cuento sobre su animal favorito, el juguete que le habían traído los abuelos de su viaje a Galicia, las piñas que había recogido con sus primos en una excursión a la montaña...) dejaron de tener un espacio y un tiempo en las aulas. Esos objetos y materiales que conectaban la vida de las criaturas y sus historias familiares con la vida en las aulas, desaparecieron. Las maestras (conversación telefónica del 22 de abril de 2021) señalan que esta situación fue bastante estricta durante los primeros meses del curso. Los niños y las niñas, que ahora ya tienen cinco años, sin embargo, lo aceptaron (como también aceptaron el resto de restricciones). También comentan que el apego a los objetos de casa es menor que en las criaturas más pequeñas. Estos objetos transicionales, utilizando el término empleado por Winnicot (1992) y otros autores y autoras (Hoyuelos (2006) señala a autores como Sptiz, Lézine o el propio Malaguzzi), con los que los niños y las niñas adquieren seguridad para entrar en relación con otros ambientes que no son el familiar, que ayudan a tolerar y aceptar mejor la ausencia y la lejanía del hogar, y cuya necesidad reaparece cuando se presenta una amenaza de privación, dejan de ser tan necesarios, en cierta manera, cuando las criaturas llevan ya algunos años en la escuela. No obstante, las maestras sí que han sentido la ausencia de estos objetos y materiales, sí que han echado de menos esa posibilidad de ir organizando las aulas y componiendo la jornada escolar contando con los objetos y materiales de las criaturas.

A largo de este estudio hemos observado, documentado y narrado historias que nos sugieren que estos objetos y materiales no sólo aportan seguridad a las criaturas sino que, además, son creadores de un currículum propio y singular de cada grupo, de cada clase. Hemos narrado historias que apuntan que estos objetos y materiales ofrecen seguridad, acogida y tranquilidad a la criatura que los trae, los muestra y comparte y que, al mismo tiempo, provocan preguntas, inquietudes, conexiones y curiosidad a los otros niños y niñas y a la maestra, en definitiva, que aportan nuevas historias que vivir en la escuela conectadas con las historias personales de cada uno y de cada una.

Ahora, las maestras cuentan que, poco a poco, los objetos y materiales vuelven a sus aulas, vuelven a llenarlas de historias que no sólo se pueden escuchar, como las noticias que se comparten durante la asamblea, sino que también se pueden tocar, observar e incluso, a veces, oler. Historias que se escoden en estos objetos y materiales que traen las criaturas y que se guardan en cajas, en estanterías, sobre las mesas o componiendo murales sobre las paredes del aula, a la espera, siempre, de continuar creando nuevas historias en las manos curiosas y alegres de las niñas, los niños y las maestras.

\section{Agradecimientos}

A las maestras, Imma Romeu y Consol Gimeno, que nos han enseñado a vivir la escuela con intensidad y pasión. A los niños y a las niñas que nos han mostrado su forma maravillosa de mirar, sentir y estar en el mundo. A la dirección y a todo el profesorado del CEIP Lluís de Santàngel (El Saler - Valencia) que nos han acogido. Por último, al grupo de investigación del proyecto RECREA con quienes hemos compartido historias y con quienes nos hemos repensado, una y otra vez, como investigadoras y como docentes en la formación inicial del profesorado.

\section{Referencias}

Aoki, T. T. (1993). Legitimating Lived Curriculum: Toward a Curricular Landscape of Multiplicity. Journal of Curriculum and Supervision, 8(5), 255-268.

Biesta, G. (2017). El bello riesgo de educar. Cada acto educativo es singular y abierto a lo imprevisto. SM

Clandinin, J. (2013). Engaging in narrative Inquiry. Left Coast Press.

Clandinin, J. Huber, J., Huber, M., Murphy, S., Murray, A., Pearce, M., y Steeves, P. (2006). Composing diverse identities. Narrative inquiries into the interwoven lives of children and teachers. Routledge.

Clandinin, J., Murphy, M., y Huber, J. (2011). Familial Curriculum Making: Re-Shaping the Curriculum Making of Teacher Education. International Journal of Early Childhood Education, 17(1), 9-31.

Delory-Monberger, C. (2007). Elementos de una antropología del sujeto intercultural. Revista Anthropos, huellas del conocimiento, $216,42-49$.

Hoyuelos, A. (2006). La estética en el pensamiento y obra pedagógica de Loris Malaguzzi. Octaedro, Rosa Sensat.

Hoyuelos, A. (2007). Documentación como narración y argumentación. Aula de Infantil, 39, 5-9.

Huber, J., Farmer, J., Reid, N., Desrochers, C., y Mckenzie-Roblee, S. (2016). The Potential of Familial and School CurriculumMaking Worlds in Teacher Education. McGill Journal of Education / Revue des sciences de l'éducation de McGill, 51(3), 1037-1059. https://doi.org/10.7202/1039627ar

Malaguzzi, L. (2001). La educación infantil en Reggio Emilia. Octaedro, Rosa Sensat.

Martín, D., Blanco, N., y Sierra, J.E. (2019). El proceso de creación curricular en estudiantes de educación secundaria. Una indagación narrativa. Profesorado. Revista de Currículum y Formación de Profesorado, 23(2), 377-395. https://doi. org/10.30827/profesorado.v23i2.9692

Molina, M.D. (2017). El mundo de Rosi. En Contreras, J. (Coord.), Enseñar tejiendo relaciones. Una aproximación narrativa a los docentes y a sus clases de Educación Infantil y Primaria (pp. 101103). Morata.

Olson, M. (2000). Curriculum as multistoried process. Canadian Journal of Education, 25(1), 169- 187. https://doi. org/10.2307/1585952

Rinaldi, C. (2011). En diálogo con Reggio Emilia: escuchar, investigar, aprender. Grupo Editorial Norma S.A.C.

Sendra, C. y Arbiol, C. (2019). Naturaleza, saber y narrativa. A la búsqueda de una relación sensible con el mundo natural y con el saber. Revista Interuniversitaria de Formación del Profesorado, 94(33.3), 159-174. https://doi.org/10.47553/rifop. v33i3.75358

Van Manen, M. (2010). El tono en la enseñanza. El lenguaje de la pedagogía. Paidós.

Winnicott, D.W. (1992). Realidad y juego. Gedisa. 
